\title{
Secretin and cholecystokin/pancreozymin in combination in the inhibition of gastric acid secretion
}

\author{
B. S. BEDI, H. T. DEBAS, A. E. O. WASUNNA, B. F. BUXTON, AND I. E. GILlESPIE \\ From the University Department of Surgery, Western Infirmary, Glasgow
}

SUMMARY Both secretin, and the single substance which possesses both cholecystokinin and pancreozymin activity, have been shown to inhibit gastric acid secretory responses. Since potentiation may occur between pairs of stimulants of gastric secretion, the effects of combining secretin and cholecystokinin/pancreozymin have been studied in Heidenhain pouches stimulated by continuous intravenous pentagastrin. Evidence suggesting potentiation between these two inhibitor agents is presented.

Inhibition of gastric acid secretion is caused when the mucosa of the upper small intestine is bathed either by fat (Feng, Hou, and Lim, 1929), acid (Sokolov, 1904) or hyperosmolar solutions (Konturek and Grossman, 1965). The studies of Andersson (1960) suggest that the inhibition caused by acid in the duodenum is mediated by a humoral agent. There is therefore interest in the possible inhibitor properties on gastric acid secretion of extracts prepared from duodenal mucosa (Jorpes, 1968). Under certain experimental conditions in dogs, relatively pure secretin (Gillespie and Grossman, 1964a; Wormsley and Grossman, 1964) and relatively pure cholecystokinin/pancreozymin (Gillespie and Grossman, 1964, Bedi, Govaerts, Master, and Gillespie, 1967) have been demonstrated to inhibit Heidenhain pouch acid responses to stimulation by gastrin and it has been suggested that these agents may in fact be the principal mediators of the inhibition.

There is evidence of potentiation at the level of the acid-producing cells between pairs of stimulants, eg, gastrin extract and stable choline ester (Gillespie and Grossman, 1964b), and gastrin and histamine (Passaro, Gillespie, and Grossman, 1964). Bedi, Debas, Gillespie, and Gillespie (1971) have also shown potentiation between bile salts and acetylcholine in the release of gastrin from the pyloric antrum. It is possible that potentiation may also exist between various inhibitors of gastric acid secretion. The present experiments were therefore designed to explore the possibility that both secretin and cholecystokinin/pancreozymin acting together may result in facilitated or potentiated inhibition.

Received for publication 17 September 1971.

\section{Materials and Methods}

The observations were made on three dogs with Heidenhain type fundic pouches, the gastrointestinal tract otherwise being intact. The dogs' weights were between 15 and $20 \mathrm{~kg}$ and all operative procedures had been completed more than three months before the present experiments.

Acid secretion from the Heidenhain pouch was stimulated by a continuous constant-rate intravenous infusion of pentagastrin at a dose which gave the maximal acid response from the Heidenhain pouch. During each experiment the secretion from the Heidenhain pouch was collected continuously, and every 15 minutes the volume was measured in millilitres and the acid concentration estimated by titration against $0.01 \mathrm{~N}$ sodium hydroxide with phenol red indicator, end-point 6.8 to $8 \cdot 4$. Acid outputs were derived from multiplication of the volume and concentration values. A plateau of acid secretion from the Heidenhain pouch to the intravenous infusion of pentagastrin was considered to have been achieved when four consecutive 15minute acid outputs varied less than $15 \%$.

The relatively pure secretin and cholecystokinin/ pancreozymin preparations were purchased from Professor Jorpes of the Karolinska Institute, Stockholm. The substance with both cholecystokinin and pancreozymin activities will hereafter be referred to simply as cholecystokinin.

At the start of each experiment two continuous intravenous infusions were established, one to infuse the pentagastrin in $0.9 \%$ saline solution, and the other with $0.9 \%$ saline for the subsequent infusion of the inhibitor agents. Once a plateau acid response to 
pentagastrin had been established, the secretin or cholecystokinin, or both combined, were given through the second continuous constant rate intravenous infusion set over a one-hour period.

Differences between test and control mean values for each 15-minute period were tested for statistical significance by Student's t-test for paired values.

\section{Results}

EFFECT OF SECRETIN ALONE ON THE ACID RESPONSE OF THE POUCH TO PENTAGASTRIN Figure 1 shows the effect of 75 clinical units of secretin infusion on the acid response of the Heidenhain pouch to the maximal dose of pentagastrin. The inhibition of acid secretion occurred rapidly after the start of the secretin infusion, being present within 15 minutes, and statistically significant for 105

\section{HEIDENHAIN POUCH DOGS}

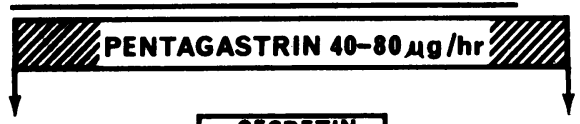

\section{ACID OUTPUT}

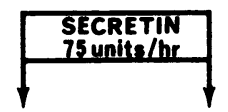

as \% of CONTROL

$100 \%=3.88 \mathrm{mEq} / \mathrm{hr}$

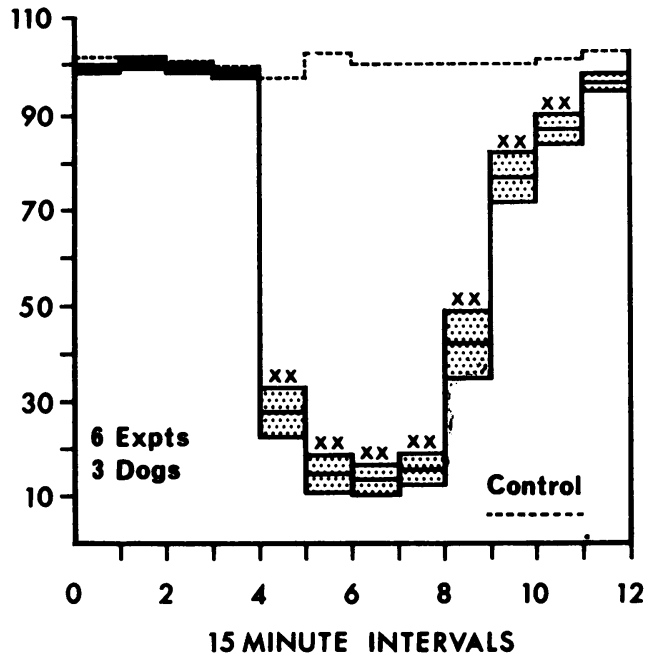

Fig. 1 The effects of an infusion of secretin on Heidenhain pouch secretion stimulated by intravenous infusion of pentagastrin.

Continuous line shows the means and shaded areas the standard errors of these means for each 15-minute acid output. The crosses denote statistically significant difference from control levels; two crosses indicate $\mathrm{P}<0.01$. minutes, after which there was a return to control levels.

EFFECT OF CHOLECYSTOKININ ALONE ON THE ACID RESPONSE OF THE HEIDENHAIN POUCH TO PENTAGASTRIN

The results of two experiments in each of the three dogs are shown in Figure 2. Seventy-five clinical units of cholecystokinin infusion over one hour caused a significant reduction of the acid response of the Heidenhain pouch to pentagastrin for 90 minutes.

\section{HEIDENHAIN POUCH DOGS}

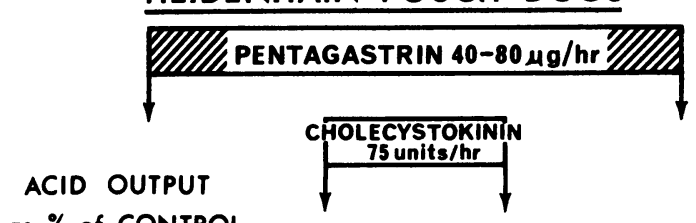

as \% of CONTROL $100 \%=3.44 \mathrm{mEq} / \mathrm{hr}$

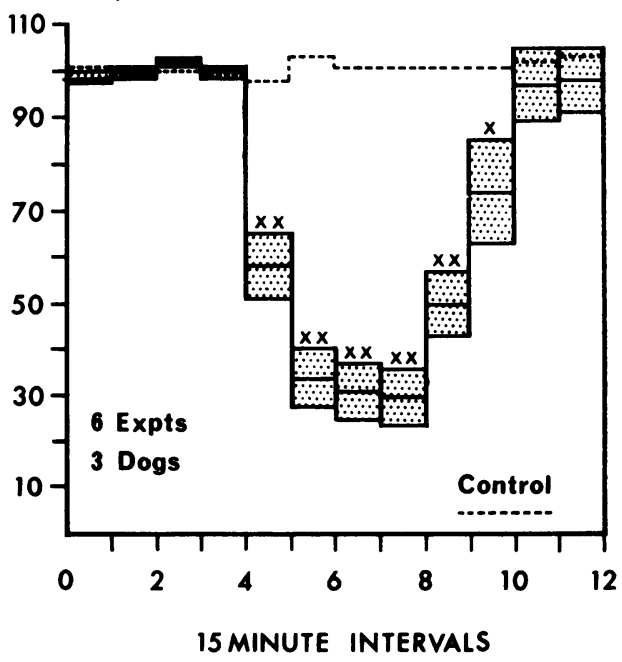

Fig. 2 The effects of an infusion of cholecystokinin on Heidenhain pouch secretion stimulated by intravenous infusion of pentagastrin.

Continuous line shows the means and shaded areas the standard errors of these means for each 15-minute acid output. The crosses denote statistically significant difference from control levels; $t$ wo crosses indicate $\mathrm{P}<0.01$ and one cross $\mathrm{P}<0.05$.

In order to determine whether the two agents given simultaneously might potentiate each other in the inhibition of acid secretion it was necessary to infuse smaller doses than those used in these foregoing experiments. It was decided to establish the doses of secretin and of cholecystokinin which, given separately, would be just subthreshold for inhibition 
of the acid response to maximal stimulation by pentagastrin, and then observe the effects of simultaneous infusion of these subthreshold doses of both agents. In this way we could apply a criterion for potentiation analogous to that employed for potentiation between two stimulants of secretion, namely, the response to the combined agents exceeding that to twice the dose of either agent given alone, proposed by Gillespie and Grossman (1964b), based on the work of Gaddum (1959).

EFFECT OF VARYING DOSES OF SECRETIN INFUSION ON ACID RESPONSE OF HEIDENHAIN POUCH TO PENTAGASTRIN

In Figure 3 are shown the results of the inhibitor dose-response studies using secretin alone. With progressive reduction in the dose of secretin there was parallel fall in both degree and duration of inhibition of acid output. With 19 units of secretin inhibition of the pentagastrin response was still present, but 9.5 clinical units of secretin failed to

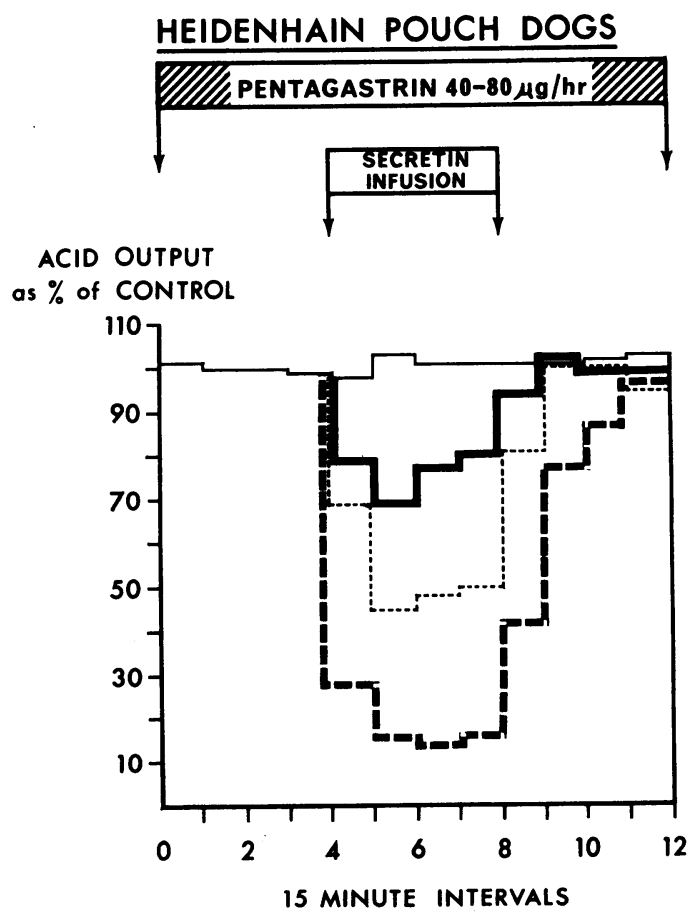

Fig. 3 The effects of infusion of 75 units (heavy interrupted line), 37.5 units (light interrupted line), and 19 units (heavy continuous line) of secretin on Heidenhain pouch acid response to intravenous infusion of pentagastrin.

In this and subsequent figures the light continuous line represents the control experiments. Six experiments in three dogs for each dose studied. give significant inhibition. Therefore $9 \cdot 5$ clinical units of secretin was regarded as a subthreshold dose for inhibition.

EFFECT OF VARYING DOSES OF CHOLECYSTOKININ INFUSION ON ACID RESPONSE OF HEIDENHAIN POUCH TO PENTAGASTRIN

The dose-response pattern to cholecystokinin infusion is shown in Figure 4. With this material

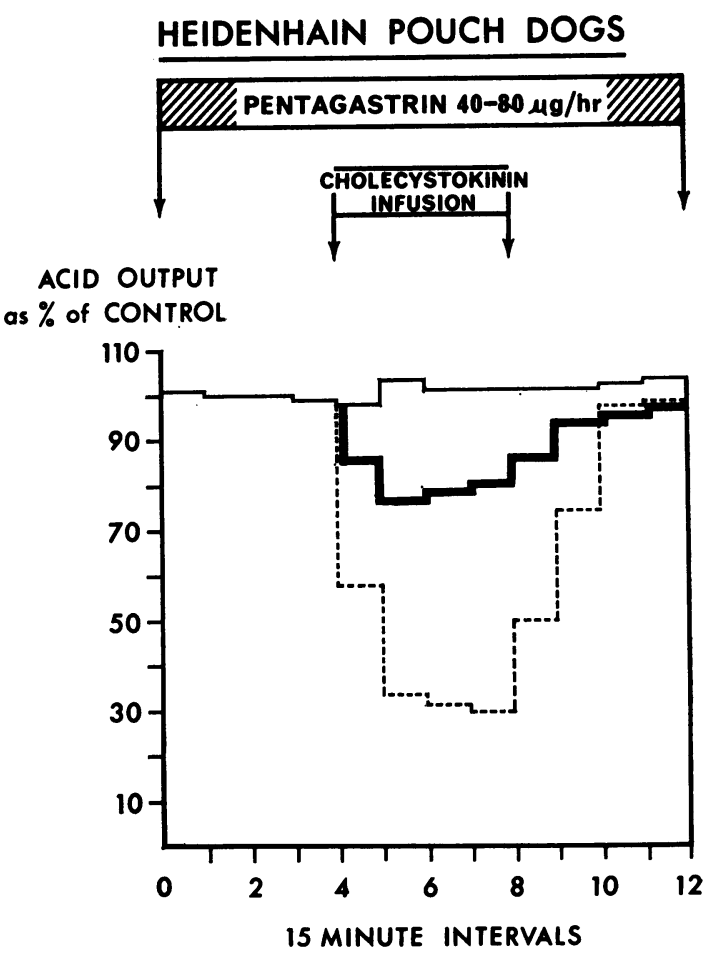

Fig. 4 The effects of infusion of 75 units (light interrupted line) and 37.5 units (heavy continuous line) of cholecystokinin on Heidenhain pouch acid response to intravenous infusion of pentagastrin. Six experiments in three dogs for each dose studied.

also there was a reduction in both the degree and duration of inhibition of acid response of the Heidenhain pouch to pentagastrin when smaller doses were infused. In this instance the subthreshold inhibitory dose of cholecystokinin was 19 clinical units.

EFFECT OF SIMULTANEOUS INFUSIONS OF
SECRETIN AND CHOLECYSTOKININ ON
HEIDENHAIN ACID RESPONSE OF POUCH TO
PENTAGASTRIN
The results of giving simultaneously the smallest 
HEIDENHAIN POUCH DOGS

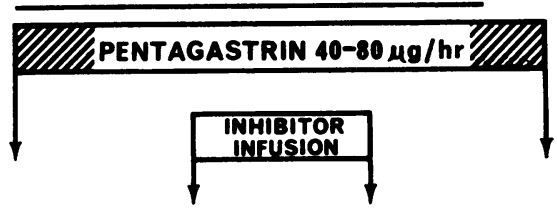

ACID OUTPUT

as \% of CONTROL

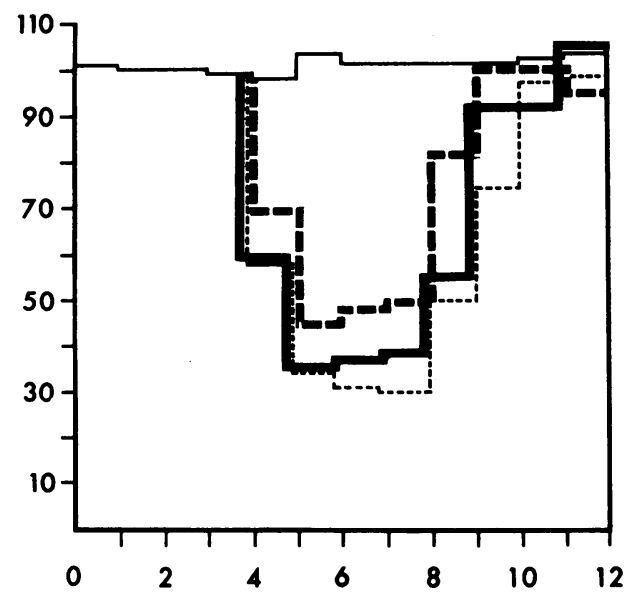

15 MINUTE INTERVALS

Fig. 5 The effects of 75 units of cholecystokinin (light interrupted line), $37 \cdot 5$ units of secretin (heavy interrupted line), and 19 units of secretin plus $37 \cdot 5$ units of cholecystokinin on Heidenhain pouch acid secretion stimulated by intravenous infusion of pentagastrin. Nine experiments in three dogs for each dose studied.

doses of secretin (19 clinical units) and of cholecystokinin ( $37 \cdot 5$ clinical units), which separately showed significant inhibition of the acid response to maximal doses of pentagastrin, are shown in Figure 5. The degree of inhibition caused by the combined infusion of the two inhibitors was not significantly different from that from twice the dose of either agent given separately.

Figure 6 shows the results of the combination of subthreshold doses, ie, 9 units of secretin and 19 units of cholecystokinin. In this instance the degree of inhibition caused by the combined two agents was greater than the inhibition by twice the dose of either agent alone, and was thus suggestive of the presence of potentiation between the two preparations in the inhibition of the maximal acid response to pentagastrin.
HEIDENHAIN POUCH DOGS

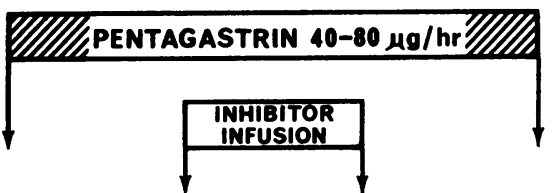

ACID OUTPUT

as \% of CONTROL

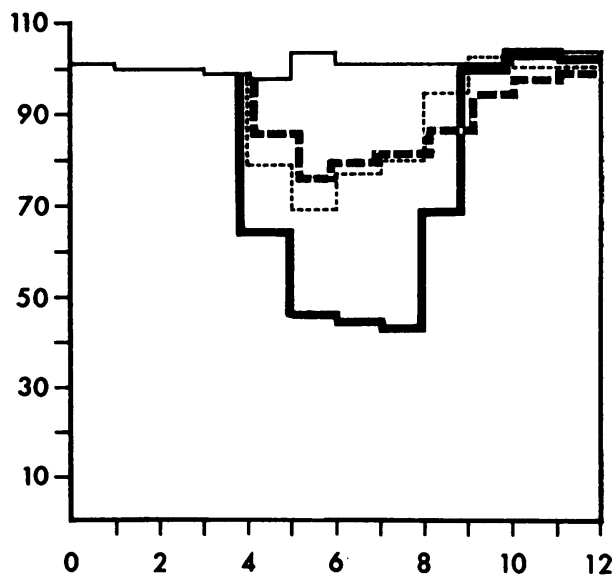

15 MINUTE INTERVALS

Fig. 6 The effects of infusion of 37.5 units of cholecystokinin (heavy interrupted line), 19 units of secretin (light interrupted line), and 9 units of secretin plus 19 units of cholecystokinin on Heidenhain pouch acid secretion stimulated by intravenous infusion of pentagastrin. Nine experiments in three dogs for each dose studied.

\section{Discussion}

A number of studies in animals have shown that as pure preparations as can be obtained of secretin alone (Wormsley and Grossman, 1964; Johnson and Grossman, 1968; Stening, Johnson, and Grossman, 1969a) and cholecystokinin are capable of inhibiting gastric acid secretion (Bedi et al, 1967; Stening, Johnson, and Grossman, 1969b). It has been suggested that secretin might account for all the inhibition of gastric acid secretion produced by duodenal acidification in the dog (Johnson and Grossman, 1968; Johnson and Grossman, 1969). Our study shows that cholecystokinin is also a strong inhibitor of pentagastrin-stimulated gastric acid secretion in the dog, and therefore suggests it may also be a contender for the role of mediation of inhibition arising from the duodenum. 
Differences in the structure of the two duodenal hormones, which have been revealed by the work of Jorpes and Mutt (1968), raise the possibility that the two agents may produce inhibition by different mechanisms. It is interesting that the C-terminal tetrapeptide sequence of cholecystokinin is identical with that of gastrin, whereas there is no apparent structural similarity between secretin and either of the other two hormones. The evidence from Grossman's laboratory (1970) suggests that the inhibition of gastric acid responses to pentagastrin by cholecystokinin is competitive, whereas that by secretin can be explained on a non-competitive basis.

Potentiation has been demonstrated between various pairs of stimulants of gastric acid secretion, eg, gastrin and histamine, gastrin and choline ester, histamine and choline ester (Gillespie and Grossman, 1964a; Passaro et al, 1964). More recently Wormsley has shown potentiated pancreatic exocrine responses from the simultaneous administration of secretin and cholecystokinin/pancreozymin(Wormsley, 1969). It would not seem too surprising, therefore, if potentiation also occurred between pairs of agents concerned with inhibition of responses. The results of our experiments employing a combination of subthreshold inhibitor doses of secretin and cholecystokinin are strongly suggestive of potentiation. It is difficult, however, to define satisfactory criteria of true potentiation when dealing with inhibition. With respect to stimulation of a secretory response, the criteria proposed by Gillespie and Grossman (1964b) on the work of Gaddum (1959), namely, that potentiation occurs to two agents given simultaneously when the response is significantly greater than that to twice the dose of either agent given alone, is reasonable, particularly when there is a long dose-response curve and large maximal response level. 'Potentiated inhibition' is a more difficult concept, and there must be some reservation about applying an analogous criterion to such a negative measurement. The 'dose-response' curve of inhibition was relatively steep, with few steps in increasing dosage of either secretin or cholecystokinin between minimal and maximal inhibition, and this may partly account for the criterion of potentiation appearing to be satisfied only for the combination of subthreshold doses of the two agents. On the other hand, in the studies of Gillespie and Grossman (1964b) on potentiation between urecholine and gastrin in the stimulation of gastric acid secretion clearest evidence of potentiation was found between the smallest doses in combination.

It is interesting to note that the degree of inhibition by the combination of subthreshold doses of secretin and cholecystokinin was about the same as achieved by endogenous acid in the duodenum (Cooke, 1968).

\section{References}

Andersson, S. (1960). Inhibitory effects of hydrochloric acid in the duodenum on gastrin-stimulated gastric secretion in Heidenhain pouch dogs. Acta physiol. scand., 50, 105-112.

Bedi, B. S., Debas, H. T., Gillespie, G., and Gillespie, I. E. (1971) Effect of bile salts on antral gastrin release. Gastroenterology, $60,256-262$.

Bedi, B. S., Govaerts, J. P., Master, S. P., and Gillespie, I. E. (1967). Inhibition of gastric acid secretion by intravenous cholecystokinin extract. Scand. J. Gastroent., 2, 68-74.

Cooke, A. R. (1968). Observations on the effect of diversion of acid from the duodenum in response to gastrin and histamine. Gastroenterology, 55, 268-271.

Feng, T. P., Hou, H. C., and Lim, R. K. S. (1929). On the mechanism of the inhibition of gastric secretion by fat. Clin. J. Physiol., 3, 371-380.

Gaddum, J. H. (1959). Pharmacology, 5th ed., pp. 504 et seq. Oxford University Press, London.

Gillespie, I. E., and Grossman, M. I. (1964a). Inhibitory effect of secretin and cholecystokinin on Heidenhain pouch responses to gastrin extract and histamine. Gut, 5, 342-345.

Gillespie, I. E., and Grossman, M. I. (1964b). Potentiation between Urecholine and gastrin extract and between Urecholine and histamine in the stimulations of Heidenhain pouches. Gut, 5 , 71-76.

Grossman, M. I. (1970). Gastrin, cholecystokinin, and secretin act on one receptor. Lancet, 1, 1088-1089.

Johnson, L. R., and Grossman, M. I. (1968). Secretin: the enterogastrone released by acid in the duodenum. Amer. J. Physiol. 215, 885-888.

Johnson, L. R., and Grossman, M. I. (1969). Characteristics of inhibition of gastric secretion by secretin. Amer. J. Physiol., 217, 1401-1404.

Jorpes, J. E. (1968). The isolation and chemistry of secretin and cholecystokinin. Gastroenterology, 55, 157-164.

Konturek, S., and Grossman, M. I. (1965). Effect of perfusion of intestinal loops with acid, fat, or dextrose on gastric secretion. Gastroenterology, 49, 481-189.

Passaro, E. P., Jr., Gillespie, I. E., and Grossman, M. I. (1964) Potentiation between gastrin and histamine in stimulation of gastric secretion. Proc. Soc. exp. Biol. (N.Y.), 114, 50-52.

Sokolov, A. P. (1904). Analysis of the secretory work of the stomach in the dog. Thesis, St. Petersburg. Cited by B. P. Babkin (1950), Secretory Mechanisms of the Digestive Glands, 2nd ed., p. 467. Hoeber, New York.

Stening, G. F., Johnson, L. R., and Grossman, M. I. (1969a). Effect of secretin on acid and pepsin secretion in cat and dog. Gastroenterology, 56, 468-475.

Stening, G. F. Johnson, L. R., and Grossman, M. I. (1969b). Effect of cholecystokinin and caerulein on gastrin- and histamineevoked gastric secretion. Gastroenterology, 57, 44-50.

Wormsley, K. G. (1969). Measurement of pancreatic exocrine function in health and disease. Brit. J. Surg., 56, 695.

Wormsley, K. G., and Grossman, M. I. (1964). Inhibition of gastric acid secretion by secretin and by endogenous acid in the duodenum. Gastroenterology, 47, 72-81. 